\title{
The History of Physiotherapy Education in South Africa
}

\author{
Extract of Speech by PROF. RAYMOND DART
}

Diploma Ceremony, Pretoria School of Physiltherapy, 10th February, 1961

I am sure that many of you, who are about to enter your professional careers, must have been wondering why an ancient retired professor, who potters about with desiccated fossils instead of living pulsating people, should have been chosen by your Society as its president.

Well, like most old men's tales, it's rather a long story and goes back to one's boyhood at least half a century ago. Then my mother, who knew herself, like most mothers, how to rub away pain and massage aches, used to summon me to soothe some of her own. Later, while a medical student in Sydney, I dissected with, and coached students of Massage and Medical Gymnastics. Later still, after diving into a swimming pool, whose end proved shallower than I had imagined it to be, I had the good fortune to be treated by one of the competent products of that School.

It may be surprising too to know that the word Physiotherapy is of such recent origin that it did not even appear in the Encyclopaedia Britannica (14th ed.), that was current in the decade 1929-1939 before the Second World War. Until then what we call Physiotherapists were known as Masseuses and Medical Gymnasts.

Shakespeare makes Juliet say to Romeo:

What's in a name? that which we call a rose,

by any other name would smell as sweet.

True enough, but in their legal phraseology the Romans said Nomen est quasi rei notamen, i.e. "A name is, as it were, the distinguishing mark of a thing". So I think it is worthwhile for me to tell you about the background in South Africa of the distinguishing mark of the thing that you go out today to proudly bear throughout your life.

That will carry us back for a moment to 1923 ; nearly 40 years ago when I arrived in Johannesburg to help build up our Witwatersrand Medical School that had started four years earlier. That year the late Miss B. G. Alexander, a splendid personality and then Matron of the Johannesburg General Hospital, had convened a Congress of South African nurses in Johannesburg, which she asked me to address.

At that time each of our four provinces had its separate Medical Council. Not until 1928, five years later did the late Dr. D. F. Malan give us a single South African Medical Council to control the status and standards of medical, tental, nursing and all other medical auxiliary personnel throughout the Union of South Africa.

Today when we have such splendid nursing colleges in each of the four provinces costing in the aggregate some millions of Rand it seems fantastic that South Africa had to await another 16 years until the Second World War for the establishment of the South African Nursing Council by further legislation in 1944 before the necessary pressure could be brought to bear upon the provinces to build up these educational institutions for nursing. When we see what has been done by our big hospitals during the last decade in the way of their training as well as nurses, physiotherapists, occupational therapists, dieticians, radiographers and other personnel, by taking Pretoria Hospital alone, we realize that the future of auxiliary medical personnel in South Africa is now well assured.

Back in 1932 though, I was shocked to find that the education of all types of auxiliary medical services from nurses to kitchen staff was nobody's legal responsibility. So in addressing the nurses assembled at the Congress, I said they might imagine they were a profession, but really they were 'neither fish, flesh nor good red herring'. Nobody in South Africa knew whether nursing education was secondary education and so fell under the Provinces or was higher education and fell under the Union Government. I advised them never to rest until they found out first of all whose responsibility their education was to be.

That grand old lady, as Miss B. G. Alexander, proved herself to be, had built up a school of Nursing at the Johannesburg General Hospital despite all the discouragements she had encountered. It was her encouragement and the steps taken soon afterwards in America at Yale University, assisted by the Rockefeller Foundation, to set up a university degree course in Nursing that led me to propose in our faculty in 1926 the establishment of Science degree courses in Nursing and in Massage and Medical Gymnastics in the University of the Witwatersrand, i.e. just three years after that Nursing Congress.

I could not have shocked my clinical medical colleagues more. They wanted to know if 1 wanted Doctors of Nursing and Massage too; but with the help of the late Dr. Ronald P. Mackenzie and Professors Cluver and Watt, the proposals passed through the Medical Faculty but were blocked by the Senate of our University.

Eight years later, in 1934, I happened to be the University's representative on the South African Medical Council. At its second meeting that or the following year a curious situation arose. The chief hospital in Cape Town (then the Somerset Hospital) had lost its Matron; its Board had been forced into accepting a highly qualified but unilingual matron from Great Britain because there was no official recognized educational authority for nurses in South Africa and no advanced education of nurses whatsoever as Matrons or Sister Tutors.

As the South African Medical Council, established by the $1928 \mathrm{Act}$, was the body now charged with registering (and with laying down the minimal standards of education for) nurses, midwives and other medical auxiliaries the Cape Hospital Board had requested the Council to establish courses, for the advanced training of nurses to take higher posts such as Matrons, Sister Tutors and so forth.

The Medical Council had no mechanism for establishing such higher nursing training so its executive committee had recommended that the Cape Hospital Board be informed accordingly. To this I objected because, although they did not have the power to set up such a teaching mechanism, a fortunate section of the Act made it their duty to report to the Minister (who was also the Minister of Education) any matter that came to their notice that affected adversely the matters with which the Council had been charged.

They were then informed of what the Johannesburg Medical School had tried to do eight years earlier; and which, had. they not been frustrated by ignorant people, would have rendered the Cape Hospital Board's application unnecessary. When they asked what should be done I suggested that they approve in principle what the Medical Faculty had tried to do; and, if approving, inform the universities having Medical Schools that the Medical Council regarded the higher education of nurses as their proper function; and inform them also about the need for such training that had come to the Council's notice. This, in due course, happened.

I had learned in the meantime that South Africa was not ripe for arranging four-year degree courses in Nursing, but we could give University Diplomas after only one year of concentrated training. So the year 1938 saw the establishment of Nursing Diploma courses at both Cape Town and Johannesburg Medical Schools; and since 1939, 152 nurses (and the public and the hospitals they have served) have 
profited by this higher education through the holding of Diplomas in Nursing from the University of the Witwatersrand alone.

Even better things, as far as Physiotherapy was concerned, were to follow. At the Nursing Committee of the Medical Council-of which Miss Alexander was then Chairmantwo requests came meantime from private individuals (or business syndicates) for the recognition of training schools for Masseurs which they proposed to set up in Johannesburg.

Familiar now with the greater advantages both to South Africa and to its nursing profession through having diplomates trained in medical schools it was unnecessary to explain what it would mean to the country to have its Masseuses also trained in Medical Schools, and the Hospitals to which the Medical Schools were attached, rather than in private teaching establishments.

In due course the two Universities then having Medical Schools were informed about what had happened and the decisions the South African Medical Council had taken. Within a brief period the University of the Witwatersrand had established a three-year's course for a Diploma in Massage and Electrotherapy. Its first three diplomates appeared in 1940.

After 14 diplomas in Massage and Electrotherapy had been awarded in 1940 and 1941 the University of the Witwatersrand changed the name to Diploma in Physiotherapy. Seventeen were awarded in 1942 and 1943. Word of this war-time change in name must have spread fast, while it was still impending, because the Chartered Society of Massage and Medical Gymnastics in Great Britain also changed its name to the Chartered Society of Physiotherapy in that same year, 1942.

Meanwhile our, University had also agreed to award a B.Sc. (Physiotherapy) if the course were extended to four years; and beginning in March 1944 no less than 198 Physiotherapists have since received that degree. So our University has produced 229 physiotherapists altogether, and became the first within the Commonwealth-as far as my knowledge goes-to adopt this nomenclature and to accord the high academic status of a degree to your profession. Today however, I hear that no less than six universities in Canada award degrees or diplomas in Physiotherapy.

Coming just when they were so badly needed, our physiotherpists played a significant part in the rehabilitation necessitated by the Second World War. They served along with this country's first medical post-graduate Diplomates in Physical Medicine, who were also produced at the University of the Witwatersrand during the War. They were the doctors in charge of most of the various military physiotherapeutic units that had been established in South Africa.

This rehabilitative war work made it apparent also that training in Occupational Therapy had to be undertaken. We started it in 1943 and the first four Diplomates in Occupational Therapy appeared in 1946. Today there are 81 . Johannesburg is therefore very proud that its Medical School, chiefly through the energy and enterprise of Dr. E. B. Woolf, who was recently elected a Senator in the Union Parliament, was responsible for the early and rapid evolution of the speciality of Physical Medicine and the training of its 300 auxiliary medical personnel in these two fundamental fields of therapy.

The rapid expansion of our first two medical schools showed that the medical needs of Southern Africa could not be met by such overcrowded schools as Cape Town and Johannesburg had become. The Pretoria Medical School was started in 1944 and was followed at six-year intervals by the Durban Medical School in 1950 and the Stellenbosch Medical School in 1956. Soon the Salisbury Medical School will open in Rhodesia.

The decade 1939-1949, so far as the Johannesburg Medical School was concerned, was unfortunately those overcrowded years of war and its aftermath; classes had even to be quadruplicated. We have never yet been in a position of being able to establish a separate School of Physiotherapy and to train as many physiotherapists as we wanted; we have never had room in Johannesburg.
The expanding profession, however, had to have expanding forces of physiotherpists and other auxiliaries and the need was seen by Dr. Woolf. So, he with the aid of Dr. R. I. Retief and W. Waks, I understand, was largely responsible for your School's existence with its first admission of ten students in 1949.

The Pretoria Medical School probably had too many staffing problems of its own in the first four years of its existence to take the same sort of paternal interest in the founding of your School that our Anatomy and Physiology Departments did in Johannesburg. Today, however, your School also has the advantage of securing its training in Anatomy and Physiology from these departments of your University.

Every young School has its teething troubles: Your first Principal, Miss M. Emslie, M.C.S.P., Superintendent Physiotherapist at the Pretoria Hospital retired after about two years and was successfully succeeded for six years by Mrs. S. Bold, M.S.C.P., with Miss Hinz as Assistant; but in 1957 we carried Miss Hinz off to Johannesburg and Mrs. Bold retired in 1958 .

That put your School in rather a sore plight until Miss Bodoano, M.C.S.P. came out from England with Miss A. J. Savin M.C.S.P. (Teacher's Certificate) in June, 1958, and inl the short intervening space of time has built up your School with its six fully qualified teachers in Physiotherapy-one a product of your own School-and 73 students in training.

At your first diploma ceremony in 1952 ten students received certificates; on the last two occasions there have been 21 . Up until today 112 physiotherapists have qualified from this School and are doing the excellent work they have been doing for a decade both here in South Africa and overseas alongside ours from Johannesburg. Before many years the total output of the Transvaal therapy schools will be over half a thousand.

Until this year your Diploma has been a Pretoria Hospital Certificate, but now the examinations have come under the Department of Education, Arts and Science, and a National Diploma Certificate is awarded. The School is, however, a Provincial School under the Department of Medical Services. By offering students contracts, whereby they undertake to work for the Province for three years in return for their three years of training, the Medical Services hope to maintain the physiotherapeutic services that all their larger hospitals require today.

So much for the Transvaal: what is the position elsewhere in the Union? The University of Cape Town initiated its three-year Diploma in Physiotherapy course in 1958 with Miss Margaret Roper from England, as its Teacher and produced its first seven Diplomates last year (1960). As yet neither the O.F.S. nor Natal have established separate schools.

Perhaps one day in Pretoria too, a degree course will be established in Physiotherapy and maybe also in Occupational Therapy. Gradually people are realizing that in a sputniklunik world", where New York is nearer to us by jet than Cape Town is by train, no woman can go far professionally without as sound a basic training in mathematics, physics and chemistry as possible.

The reasons I have been recalling some of these early facts about how Physiotherapy came to be established in South Africa are several. In the first place I wanted you to realize how recent yet how potent is the whole of what you have been learning in South Africa and therefore how fortunate you are to be pioneers in your chosen profession. You are determining collectively its future reputation for value and usefulness in Preventive and Curative Medicine throughout this vast continent of Africa.

A second reason was to show the high ideals that the initiators of that education had, and continue to retain for your professional status. Fifty years ago in Australia massage training involved the dissection of the human body. From experience I knew how important for my friends amongst the masseuses this was; I could not imagine that anything less would be the best for physiotherapists in South Africa.

(Continued on page 5) 


\title{
TREATMENT NOTES
}

\section{SOME SUGGESTIONS IN THE REHABILITATION OF HEMIPLEGICS}

\author{
E. JENNINGS, M.C.S.P.
}

A. In Early Flaccid Stage:

(1) Teaching the patient to roll over by themselves onto their unaffected side.

Three actions:-

(a) Lifting the affected arm across the chest.

(b) Wriggling the toes of the unaffected side under the Tendo-Achilles of the other foot and so obtaining leverage to bring the affected leg over.

(c) Grasping the side of the bed towards which she wants to turn, and then pulling with the arm and leg and at the same time turning the head.

See Diagram I.

(2) Use of rope attached to the lower corners of the bed.

The length of this rope must be adjusted to be just long enough for the patient to reach with her outstretched unaffected hand. A padded area in the middle of the rope facilitates the grasp; this can be kept in position by adhesive strapping.

The patient should be given a crook stick to bring the rope within her reach.

Most patients will be able to sit up with the use of this rope within a few days.

N.B. A single centrally placed rope with a wooden handle is dangerous, as there is no side to side control.

See Diagram I.

(3) Foot Board.

This is a 4 " cubical piece of wood, 6" longer than the span between the legs of the bed. Two semicircular scallops are cut out of one side to fit against the legs of the bed and prevent it from slipping sideways.

\section{PROF. RAYMOND DART (continued from page 4)}

Thirdly, I have done it to show how words take on the meaning that we give to them by the sort of lives we lead, and also how inter-related all professional progress happens to be. There is a great tendency amongst immature human beings to imagine they increase their own importance not by self-improvement but by deriding others; or by insinuating that groups of workers other than their own particular class are of lesser value in the general scheme of things. You will often hear superficial thinkers say "Oh! what can she know about it? She's only a nurse", or, "How can he know? He's only a labourer, a shop assistant, a bricklayer, or what not". It was through doctors and nurses caring for the welfare and elevated status of all medical auxiliaries that led to what has been done so far for you and your education and through you for sick South Africans.

Finally, I hope that I have indicated, through what has lain behind and happened to your profession in South Africa during the past 40 years, something of the avalanching developments you can anticipate during the 40 years that now lie in front of you. Those developments are in your hands.

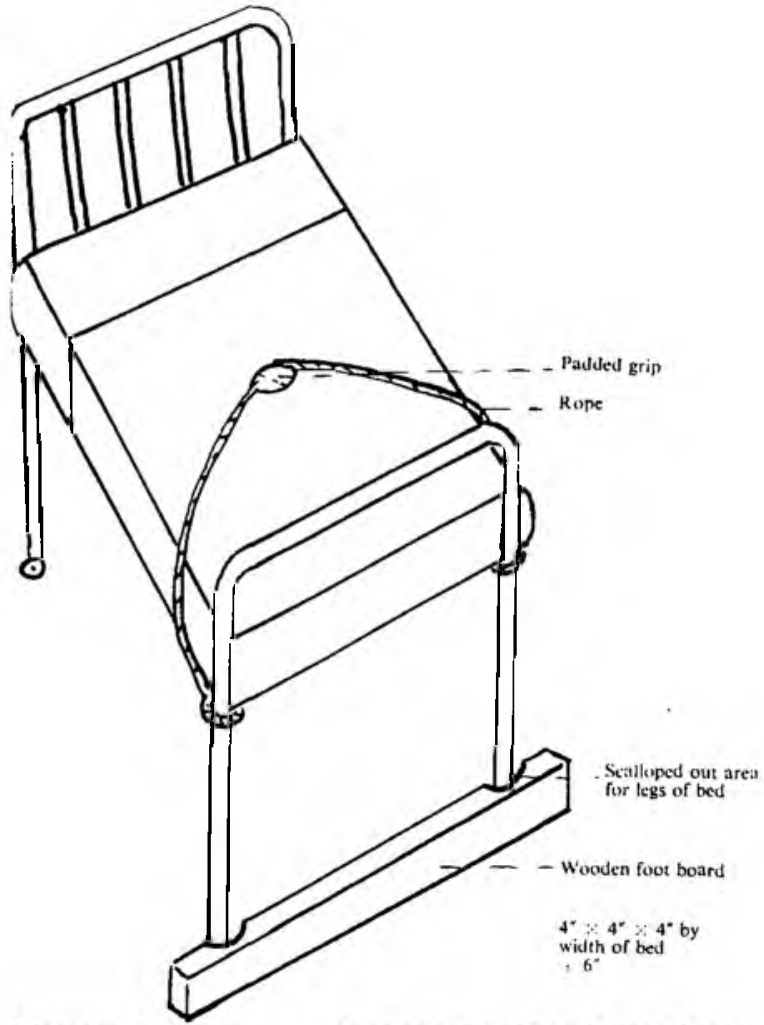

Diagram I

Rope attachment and Foot Board.

Use: The board is placed on the floor at either end of the bed (head preferably, for height). The patient is brought up to it in a chair and her feet are placed slightly apart against it on the ground. This prevents her weak leg from slipping under the bed and greatly assists the physiotherapist in her efforts to get the patient to stand up and sit down and to balance in standing. The patient of course pulls herself up, but the physiotherapist (standing on the affected side) holds the hand in position and encourages the patient to push upwards with both legs. The wooden bar also prevents the bed from moving.

\section{B. Walking Stage:}

As soon as the patient can balance herself in sitting and standing, walking is commenced. There are many methods; here are a few which I have found useful:-

(1) Assisting on the affected side. The patient supports herself in the parallel bars or on a hand-rail round the room.

N.B. Backward walking is almost as easy as forwards walking.

A chair is placed at either end of the bars.

The bars must be low enough for the patient to lean over slightly to the unaffected side.

See Diagram II 